\title{
Comparing Recurrence and Retreatment of Three Doses of Bevacizumab in Treating Severe Retinopathy of Prematurity
}

\author{
Jay Chopra ${ }^{1}$, Charline Boente ${ }^{2}$
}

1. Indiana University School of Medicine, Indianapolis, IN; 2. Indiana University School of Medicine, Department of Ophthalmology, Indianapolis, IN

Purpose: To determine recurrence and retreatment patterns after treatment of severe retinopathy of Prematurity (ROP) with either $0.5 \mathrm{mg}, 0.25 \mathrm{mg}$, or $0.125 \mathrm{mg}$ of intravitreal bevacizumab for retinopathy of prematurity.

Methods: In this retrospective chart review, data was examined for babies who had severe ROP and were treated with intravitreal bevacizumab doses of either $0.500 \mathrm{mg}, 0.250 \mathrm{mg}$, or $0.125 \mathrm{mg}$ at Riley Hospital for Children in Indianapolis from 2014 to 2021. Data collected included demographic information, past medical history, and characteristics of ROP. The data was statistically analyzed using SPSS software.

Results: One eye was analyzed for each baby. Out of 85 babies, 79 babies were included in the study. 26 babies were treated with $0.125 \mathrm{mg}$ bevacizumab, 37 with $0.25 \mathrm{mg}$, and 16 with 0.5 $\mathrm{mg}$. All babies showed initial response to the bevacizumab, with 61 babies $(77.2 \%)$ receiving retreatment with laser for either recurrence or persistent avascular retina. While the babies treated with lower doses had higher percentages of retreatment (23 babies $(88.5 \%)$ in the 0.125 $\mathrm{mg}, 29$ babies (78.4\%) in the $0.25 \mathrm{mg}$, and 9 babies (56.3\%) in the $0.5 \mathrm{mg}$ group), the difference was not statistically significant $(p=0.069)$. Most of the retreatments were due to recurrence of ROP (0.125 mg: 20 (87.0\%), $0.25 \mathrm{mg}: 19$ (65.5\%), $0.50 \mathrm{mg}: 8$ (88.9\%)) ( $p=0.339)$. On average, the babies in the $0.125 \mathrm{mg}$ group were retreated with laser at 3.4 weeks earlier gestational age and 4.7 weeks sooner after initial treatment than the higher dosing groups, however, this difference was not statistically significant $(p=0.181, p=0.287)$.

Conclusion: The outcomes comparing three doses of intravitreal bevacizumab for severe ROP showed a slight variation in recurrence and retreatment patterns but no statistically significant difference in our study. 